\title{
The psychotic transference in groups
}

\author{
Vollon Clarisse, Gimenez Guy and Christian Bonnet
}

We wish to present a study of psychotic transference in groups, following on from the work of W.R. Bion and Foulkes. We put forward the hypothesis that in the early stages of such a therapeutic group, group psychotic transference oscillates between expansive movements and restrictive movements. This will be expressed by a tendency of the patients to withdraw, either exclude himself, or engage in an undifferentiated way. To illustrate our premise, we will rely on the analysis of the early stages of a psychoanalytic psychodrama session conducted in a hospital unit. The results will enable us to rethink the therapeutic stakes for this type of treatment.

Key words: Group, psychosis, transference, envelop, matrix

\section{Introduction}

Therapeutic groups for psychotic patients require a setting which will take into account the variety of communications likely to arise in the sessions, and also and above all the intensity of the anxieties which flood each participant. These settings may bring the clinician to challenge psychoanalytic group models. Thus, in an earlier work (Vollon et al., 2015), we have been thinking about these treatments according to matrix models (Foulkes, [1964] 1984) and the group model as envelope (Anzieu, 1975). We suggested that the matrix networks are surrounded by a psychic envelope the texture of which is porous when the group is made up of psychotic patients: the work of the 
therapist being the reduction of this porosity in order to stabilize communication networks. But we have not specified the modalities of the patients' psychic contributions in these groups, which may constitute de facto a limitation to our proposals. In his commentary, Nitzgen (2015) then suggests comparing the porosity of the psychic matrix with the way in which group members can contribute mutually when the dynamic oscillates between aggregation and massification (Hopper, 2003). Our objective here is to discuss this comparison by defining the nature of psychotic transference in a therapeutic group in order to help the psychotic patients to become 'relatively healthier' (Pines, 2002: 13). From this perspective, we maintain the following hypothesis: in the early stages of a therapeutic group, the group psychotic transference oscillates between expansive movements and restrictive movements. It will get expressed by a tendency in the patients either to withdraw into themselves, or exclude themselves, or contribute in an undifferentiated way.

\section{Psychotic transference}

Let us go back for a start to the notion of psychotic transference. Freudian observations on the transference of President Schreber towards his doctor provide two important insights on the nature of transference in psychotic patients. First, the transference of these patients is linked to past infantile experiences (those of early development marked by auto-erotism) and adjoin the evolution of florid formations. Second, psychotic patients can harbour towards their therapist either transference marked by some positivity or some negativity, mainly as splitting and projection (Freud, 1911: 263).

The study of this double movement in the psychotic transference has been investigated by Melanie Klein, who stressed very early on in her work, a combined positive and negative transference in psychosis, both requiring an analysis: 'the fact that schizophrenic patients are capable of developing as much positive transference as negative transference has been fully understood; . . . one cannot be analysed without the other'. Following on from a psychodynamic approach to psychotic transference, Bion (1967) does not refer to the terms 'positive' and 'negative' to but locates it in an alternation of two specific movements: expansion and restriction. Expansion (or the patient's maximal capacity to relate) in the transference is characterized, according to Bion (1967), by a predominance of projective identification the object of which is the analyst: 'The relationship with the analyst is premature, precipitate, and intensely 
dependent' (1967: 37). This dependency can be riddled with hate elements, since Bion stresses the supremacy of destructive drives that can be so strong in the schizophrenic patient as to impregnate love drives and turn them into sadism. He stresses also, a hate of reality which may extend into all aspects of the schizophrenic's psyche (Bion, 1967: 37). On the other hand, Bion suggests that the intense dependency which marks the expansive nature of the relationship, brings about painful confusional states in the sense that is understood by Rosenfeld (1965), that is to say the patient's fear of being himself the object of intrusion of which he has been the instigator with the negative and positive parts of his personality in the projective identification (1965: 205).

At the same time, Bleger (1967) describes a similar bond in the transferential relationship between the psychotic patient and his therapist, equally characterized by a predominance of projective movements as well as confusional states. He then speaks of symbiosis (Bleger, 1967: 46). This relationship is, for him, the site of immobilization and control of the most primitive ego structures in relation to internal or external objects (Bleger, 1967: 47). Searles also refers to the term 'symbiosis' to characterize the relationship between the psychotic patient and his therapist, a relationship which can be felt as ambivalent with hate impulses. He names this specifically:

the term of 'therapeutic symbiosis' such as I understand it here included . . . a symbiosis felt as complete union in the adoration and perfect contentment which, genetically, are linked to very early mother-infant experiences, before elements of hate are introduced into this unity and transform its affective matrix into a source of overwhelming ambivalence. (Searles, 1979: 17)

In order to defend against these confusional states, the patient will resort to restriction, that is to say reduce his capacity to invest into the relationship with his analyst. It is this oscillation between expansive and restrictive movements which characterize psychotic transference: 'Harassed by the mutilations and striving to escape the confusional states, the patient returns to the restricted relationship. Oscillation between the attempt to broaden the contact and the attempt to restrict continues throughout the analysis' (Bion, 1967: 46).

To account for these different transference movements, and modalities of possible work, one of us (Gimenez, 2010) has drawn up three fundamental parts in the transference of psychotic patients. A first part where the therapist is either totally excluded from the encounter, or massively invested in the transference 'as if he is a part of the patient 
or his extension, a narcissistic pseudopod' (Gimenez, 2010: 142). It is the state of ambivalent symbiosis described by Searles, which corresponds also to what Winnicott (1969) described as 'an extension of me' underpinned by a 'primary confusional state' referring to the notion of Rosenfeld's confusional state previously mentioned. A second time where the therapist is invested as a narcissistic double: here, it is about the bi-triangulation described by Green (1980): 'the narcissistic double is thus the (narcissistic) part of the subject fitted with a (living) object invested in the negative transference and depository of the subject's primary narcissism, that is to say his "ego ideal"' (1980: 144).

Finally, a third part where the therapist is invested as an object which gradually becomes differentiated as 'third potential' (Green, 1980: 145).

\section{Psychotic transference in group situation}

Although Freud never studied transference in groups, he detected that horde formations promote particular phenomena. The individual libidinally invests the other members and the group leader, leading to a stronger link between the members of a same group and a contagion of the affects experienced. In Totem and taboo, Freud (1913) explains the functioning of group formations via the use of the myth of the primitive horde which it created and that of civilization. He then puts forward the existence of fundamental taboos pertaining to prohibited behaviour between the members of a same group, notably in sexual and hostile relationships (Freud, 1913: 15). But it will take a few more years before authors become specifically interested in relationships between members of a same group. Thus, thanks to his experience of groups at the Tavistock Clinic, Bion (1961) spotted the existence of affective movements in groups which shaped relationships between individuals, providing insights into on-going participations, and therefore of transferential movements which he named 'basic assumptions'. Bion (1961) then distinguishes three types of basic assumptions: dependency (the group gets together to be supported by a conductor on whom it depends), pairing (the group organizes itself from a symbolic couple or a sub-group which is created in the group), fight-flight (the group gets together with aim of attacking a shared object, or to escape according to the psychic danger of the situation). Following on from the work of Bion and Anzieu (1975), in the same period, Foulkes (1975) detects the existence of three types of transference in the group situation: a transference directed at the group conductor (or supervisor, 
it is the central transference), a transference between group members (also called lateral transference), and a third type of transference directed to the group itself as object. He specifies, on the other hand, that the nature of these transferences differs according to the constitution of the group: the smaller the group, the more transferential movements will be underpinned by maternal imagos. Anzieu (1972) takes up the Freudian idea of regression in group situation: according to him, it is located at the level of oral sadism and the return to the modalities of functioning specific to the early relationships mother-infant (1972: 203). The group no longer organizes itself around incest taboo and killing of the father, but on the devouring of the mother punished by weaning. At this moment in the group, central transference, that is, transference towards the conductor is massive, at the expense of transference on the group-as-object and lateral transfers (Anzieu, 1972: 211). Finally, Kaës (2005) has described more recently the mechanism of diffraction, which is anticipated in the Freudian description of dream work and which consists of an inversed condensation mechanism. From an economic point of view, the charges of group transference become 'distributed', according to him, among the group members without becoming concentrated exclusively on to one same object. It is this mechanism of diffraction which can sometimes make difficult the analysis of the transference (Kaës, 2005: 27). Along with the work of Bion (1961), Anzieu (1972, 1975), and Kaës (2005), we can observe that group transference presents some specificities such as the existence of important regressive movements or the existence of a plurality of transference movements according to the object which may be invested in the centre of the group by the participants. But can group psychotic transference be reduced to a simple superposition of psychotic transference described in the literature (that is to say an alternation of characteristics, between restriction and expansion), to those of group transference which we have just discussed? Even though there are not much studies dealing specifically with group psychotic transference, those of Foulkes ([1964] 1984, 1972), Resnik (1999), and Enjalbert (2001) can be illuminating in order to start to formulate an answer to this question.

\section{To the origins of the notion of group psychotic transference}

Foulkes is the first one to have described clinical group experiences with these patients, but he did not describe the psychotic transference. However, he suggested globally that group transference differs 
from that lived by individual set-ups, for example, in his article 'Note on transference in groups' (Foukles, 1969) when he says that 'the group members do not accept transference in the sense that we, as trained analysts, do most of the time. The group, on the contrary, defends itself, corrects statements, disputes and puts the speakers right' (Foulkes, 1969: 135), or in another article 'Oedipus conflict and regression' (Foulkes, 1972) when he says that 'as has already been observed, oedipal reactions and transference neuroses are less obvious and less concentrated on the therapist in the group than in the individual psychoanalytic situation' (1972: 245).

But it is in 1971, in his article Access to unconscious processes in the group analytic group, that he studies on going functions and processes in the transference in groups. The group transfer whether it is negative or positive is always a function of resistance. It can be resistance to change: group members may be attached to interact on the modalities of repetition or a status quo. It can also be a resistance to face what the patient might recognize as elements belonging to his internal world: he will tend to project these elements inside the group. Finally, group transference can be a resistance in the relationship with other group members and the therapist: the negative transference characterized by hate, rebellion and opposition will interfere with potential acceptance and tolerance of what is happening in the heart of the group (Foulkes, 1971).

More recently, studies by Resnik (1999) describe body manifestations of psychotic patients' transference in groups. It seems to be a form of projective identification in which sensory elements projected into the psyche and the body of the analyst await being transformed and represented by him. Finally, Enjalbert (2001) has demonstrated certain specifies of psychotic transference. In group situations, it would be about a split parental figure, support of a multitude of possible experiences for psychotic patients. Thus, the group would make possible the experimenting of moments of fusional abandonment, projecting and eventually introjecting good objects incarnated in the other group members, reach regressive problematics, to delude themselves and defend against their anxieties, recover the boundaries of their bodies by the limits of the group (Enjalbert, 2001: 139). Foulkes and Resnik do not describe transference in its regressive dimension for psychotic patients in groups, bringing up more willingly the function of this transference in terms of resistance (Foulkes, 1971) notably. On the other hand, psychotic transference in groups is characterized by projective mechanisms (Resnik, 1999), as Freud 
described in the transference of President Schreber on to the face of his doctor. Our clinical experience with therapeutic groups of psychotic patients has shown to us that in fact there was a preponderance of projective mechanisms in these settings, but we could also observe the alternation of qualities of the transfer previously described (Bion, 1967), that is to say an alternation between restriction and expansion of contributions.

\section{Psychotic group transference, clinical illustrations}

We shall now present the first two sessions of a psychoanalytic psychodrama group which we conducted in a treatment and readmission unit. It is semi-open and intended for psychotic patients by medical referral (According to Foulkes' pre-group the model, 1959). We share the idea of Foulkes' (1948) reprise by Malcolm Pines (1994: 129) that the dynamic administrator is responsible for the control of boundaries, the determination of who enters and leaves the group, for the boundaries of time and place, we have established from the earliest sessions, rules of free association (each one is invited to say what springs to his mind), respect of the word, punctuality, confidentiality regarding what is said and happens in the sessions, and the requirement to invent scenarios. The psychodrama unfolds in three stages: a first stage devoted to the construction of the scenario and the designation of the players, a second stage dedicated to the play in the scenic space, and a third allocated to review and to analyse with the whole group what has been played out. Four patients participated in this group: Lilian, 68; Sarah, 41; Nathalie, 45; and Lydia, 43 years (patients who participated to this set up specifically for three of them a paranoid schizophrenia and the other three an infantile psychosis).

The observation of withdrawal attitudes in the group. In the first exchanges, Lilian talks to the psychologist: 'yesterday it was raining, and then I started to cry, cry in my room, cry for my mother, because my mother died'. Sarah goes on while looking at her: 'I have had property stolen in the night, I am scared, I have had cream and 15 euros stolen'. The therapist feels that the interventions of Liliane and Sarah have no obvious connection between them: she begins to feel a certain internal dissociation induced by this discordant cacophony, which often precedes the emergence of an associative group chain in these types of groups (Gimenez, 2006). Liliane continues, while still looking at her intensively: 'My brother isn't that a scene?'. As the therapist is about to respond, starts a rapid succession of short and similar interventions from Sarah, Nathalie, and Liliane. They 
interrupt each other's words and avoid each other's gaze, they address themselves to the psychologist. Sarah goes on 'and I lost my father and my sister'; Nathalie continues, 'and I lost my fiancé, my mother and my father', followed by Liliane: 'I lost my grandmother'. As the group conductors record that a lot of grief circulates in the group, the patients tackle the themes of death and loss. Then Nathalie goes on, 'I am waiting for the doors to open'.

Liliane replies with irritation, still addressing herself to the psychologist: 'But that one hasn 't stopped talking about her room'.

At first, we can notice here that the patients do not look at one another and do speak to one another directly. They do not appear to exist for one another, as if they are excluding one another sensorially, to the extent that their respective associative links have, a priori, no connection. Thus, when Liliane expresses sadness, Sarah evokes, in echo, a scenario of intrusion (by the theft of personal property). We put forward the hypothesis that this exclusion is the expression of a weak investment between the group members, or investments marked by restriction (Bion, 1967). Thus, even when Nathalie, Sarah and Liliane talk about the death of close members of their families, they address themselves directly to their psychologist, without taking into account their respective words. These observations are close to Bion's (1967) description of schizophrenic patients experiencing this restriction: "Whether the patient walks straight past me into the consulting room as if scarcely aware of my presence, or whether he displays an effusive, mirthless bonhomie, the restricted relationship is unmistakable' (1967: 38-39). Indeed, we find in these patients a sensory exclusion spotted in the very first psychodrama session. We can also notice that this restriction alternates with hostile movements as testified by the irritation of Liliane following Nathalie's intervention on the opening of the pavilion's doors. We can then assume that it is here a timid manifestation but nevertheless concomitant of more expansive transference movements. The beginning of the second session will confirm the presence of this movement.

The observation of an attempt to engulf the group. At the beginning of the second session, Liliane is the first one to verbalize her wish to play: 'I want to play a drama, where I am in my room and I pray'. Sarah immediately reacts in echo, and turns towards her saying that she feels the same. After ensuring that the whole group agrees to play this scenario, the psychologist invites Liliane and Sarah to find a first 
name and an age for their characters. On stage, both patients stand close to each other, motionless, face to face and look at each other with intensity. Sarah begins to improvise: 'I love you so much, I will love you all my life even if you die, you will go to paradise to play with your ancestors'. In spite of the instructions to pretend, she takes the hands of Liliane in her hands. The latter continues, 'we'll go shopping together, I also love you, you are beautiful, you have beautiful hair, I also have beautiful hair, don't I have beautiful hair?'. The psychologist internally associates an image of Siamese twins with the posture of the two patients on the stage, as if the two patients gradually come to form one motionless body with two heads.

Contrary to the first session, we can notice here that the patients look at each other, they interact directly between themselves until they both experience the shared wish, to play. We put forward the hypothesis here, that expansive transferential movements are expressed (Bion, 1967), these same movements which had been observed in a lesser measure in the form of hostile motions in the first session. We can detect here the expression of a fusional even symbiotic link (Bleger, 1967) between the two patients in play: their bodily attitudes are identical, face to face, motionless, they look at each other with intensity. Everything seems to proceed as if a confusion gradually developed between them, the expression of which finds a figuration in the Siamese fantasy which emerges in the imagination of the spectator psychologist. Their verbal exchanges are also reminiscent of twinning. They declare their mutual love as well as the wish to eternalize this relationship: Sarah expresses her determination to love Liliane all her life, and the latter evokes that they may go shopping together. Nothing seems to want to separate them, no third party seems able to intervene in their relationship, not even the death of Sarah (Sarah will continue to love Liliane even if she dies). Only the stopping of the play by the psychologist, due to the transgression of the rule of not touching, turns out to be the only possibility for containing and limit the emergence of this investment. It is possible that this symbiotic link is the expression of a crossed projective identification: they appear to recognize each in the other, what is the most lovable (Searles, 1979) is notably when Liliane covers Sarah with compliments, quickly sending her back to her own physical appearance. They then merge into a same movement, the contact of their hands act out this protoplasmic link. Thus, it would seem that these two patients massively and reciprocally invest each other, between pseudopods and double narcissistic (Gimenez, 2010). 
Analysis of transferential movement in the first two sessions of a psychodrama. The manifestation of restrictive and expansive transferential movements in the participants can be observed in this type of psychoanalytic psychodrama group. In fact, we have been able to record in Liliane's contributions during the first session, the expression of simultaneous and opposite libidinal investments: a hostile movement towards Nathalie and an attitude of seduction towards the psychologist, expressed by an obvious good capacity for adaptation to the set up (when she asks what would constitute, or not, a play scenario). At the same time, Liliane experiences a double restrictive transferential movement towards Nathalie and expansive movement towards the psychologist. Despite the hostile motions addressed towards Liliane and her internal objects (Bion, 1967), the seductive attitude towards the psychologist could be seen as the expression of an intense dependency (Bion, 1967) or of a therapeutic symbiosis (Searles, 1965) which characterizes the first stages of a relationship between therapist and the psychotic patient. We can then detect that the restrictive and expansive transferential movements during the early stages of this group are not exclusively directed towards one unique patient (Liliane does not show any seductive attitude towards Nathalie), but is distributed towards several participants including the psychologist. This phenomena recalls the diffraction mechanism described by Kaës (1994) in the transference in group situation which he views as 'the successive or simultaneous replacement of the relationship between several objects organized with in the structures of an internal group, by the acted and imaginary relationship established in the group with different objects and the connections which constitute it' (1994: 103). In the other words, the diffraction of the transfer corresponds to an economic distribution of the impulse loads associated with the object of the transfer on several members of this group. Thus, psychotic patients in a therapeutic group setting would be able to experience a variety of relationships supported by contrasted transferential movements diluted over all the members of the group. We can then better understand how psychotic patients can be made to better apprehend, in group situation, parts of themselves as yet unexplored (Gimenez, 2006).

\section{Conclusion}

In conclusion, we have tried to show here that psychotic group transference is characterized by a set of complex movements, between restriction and expansion, which get expressed by attitudes and 
modalities of specific interaction modalities between the participants. More specifically, we noticed that each patient, from the very beginning of the session, were lead to distribute their libidinal investments on to the other members of the group in a varied even antagonistic way, oscillating in their exchanges between a tendency towards withdrawal and exclusion, and a tendency towards fusional abandonment even undifferentiation. De facto, aggregation and massification (Hopper, 2003) are not the only investment modalities of transferential investments that we can notice in the early stages of a therapeutic group with psychotic patients. Thus, from our clinical illustrations, we believe that one of the therapeutic aims of this type of treatment by the 'group conductor' (Pines, 1994) is to enable the patients to apprehend these different transferential movements one after the other, as many expressions of their internal world, unexplored by themselves (Gimenez, 2006). This work can then be regarded as a first stage in the development of a 'positive' transference (Ulric and Ivesic, 2015) in these patients in a group setting.

\section{References}

Anzieu D (1972) Le Travail Psychanalytique Dans Les Groups [Psychoanalytic Work in Groups]. Paris: Dunod.

Anzieu D (1975) Le Groupe Et L'inconscient [The Group and the Unconscious]. Paris: Dunod.

Bion WR (1961) Experiences in Groups. London: Tavistock.

Bion WR (1967) Second Thoughts. London: William Heinemann Medical Books Limited. Bleger J (1967) Symbiose Et Ambiguïté [Symbiosis and Ambiguity]. Paris: Presses Universitaires de France.

Enjalbert M (2001) 'Le groupe, le sujet et le schizophrène' [The group, the subject and the schizophrenic]. Revue De Psychothérapie Psychanalytique De Groupe 46: $137-144$.

Foulkes SH (1948) Introduction to Group-Analytic Psychotherapy. London: Karnac Books.

Foulkes SH ([1964] 1984) Therapeutic Group Analysis. London: Karnac Books.

Foulkes SH (1969) Note on transference in groups. Group Analysis 3: 135-146.

Foulkes SH (1972) Oedipus conflict and regression. In: Foulkes SH (ed.) Selected Papers of S.H. Foulkes: Psychoanalysis and Group Analysis. London: Karnac Books, pp. 235-247.

Foulkes SH (1975) The leader in the group. In: Foulkes SH (ed.) Selected Papers of S.H. Foulkes: Psychoanalysis and Group Analysis. London: Karnac Books, p. 173.

Freud S (1911) Remarques Psychanalytiques Sur Un Cas De Paranoïa [Psychoanalytic Notes on a Case of Paranoia]. Paris: Presses Universitaires de France.

Freud S (1913) Totem Et Tabou [Totem and Taboo]. Paris: Presses Universitaires de France.

Freud S (1923) Le Moi Et Le Ça [The Ego and the Id]. Paris: Presses Universitaires de France. 
Gimenez G (2006) 'La construction d'une chaîne associative groupale dans le travail psychanalytique avec les patients psychotiques en groupe: du chaos dissociant à une possible polyphonie' [The construction of a group associative chain in psychoanalytic work with group psychotic patients: Dissociative chaos to a possible polyphony]. Revue Française De Psychothérapie Psychanalytique De Groupe 47: 79-91.

Gimenez G (2010) Halluciner, Percevoir L'impensé [Hallucinated, Collect the Unthought]. Bruxelles: De Boeck.

Green A (1980) Narcissisme De Vie. Narcissisme De Mort [Life Narcissism and Death Narcissism]. Paris: Éd. de Minuit.

Hopper E (2003) Traumatic Experience in the Unconscious Life of Group. London: Karnac Books.

Ivezić S and Urlić I (2015) The ability to use the group as a corrective symbiotic object in group analytic psychotherapy for patients with psychoses. Group Analysis 48: 315-331.

Kaës R (1994) La Parole Et Le Lien [The Word and the Link]. Paris: Dunod.

Kaës R (2005) 'Groupes internes, et groupalité psychique: genèse et enjeux d'un concept' [Internal groups, and psychic groupality: Genesis and challenges of a concept]. Revue De Psychothérapie Psychanalytique De Groupe 45: 9-30.

Nitzgen D (2015) The matrix and the envelope. A comment on Vollon, Gimenez and Bonnet's, the notion of the 'matrix': New perspectives in group psychotherapy for psychotic patients. Group Analysis 48(2): 202-207.

Pines M (1994) Ring of Fire, Primitive Affect and Objects Relations in Group Psychotherapy. London: Routledge.

Pines M (2002) The coherency of group analysis. Group Analysis 35(1): 13-26.

Resnik S (1999) Le Temps Des Glaciations [The Time of the Glaciations]. Paris: Erès.

Rosenfeld H (1965) Etats Psychotiques [Psychotic Psychic Position]. Paris: Presses Universitaires de France.

Searles H (1965) L'effort Pour Rendre L'autre Fou [The Effort to Make the Other Crazy]. Paris: Gallimard.

Searles H (1979) Le Contre-transfert [The Countertransference]. Paris: Folio Essais.

Vollon C, Gimenez G and Bonnet C (2015) The notion of the 'matrix': New perspectives in group psychotherapy for psychotic patients. Group Analysis 48(2): 174-186.

Winnicott D (1969) De La Pédiatrie À La Psychoanalyse [From Pediatric to Psychoanalysis]. Paris: Broché.

Vollon Clarisse, PHD, temporary assistant professor in University of Paris Descartes, Psychologist and supervisor in liberal. Address: Aix-Marseille University, LPCLS EA 3278 13621, Aix-en-Provence, France. Email: Vollonclarisse@gmail.com

Gimenez Guy, Professeur, director of clinical psychology laboratory at the University Aix-Marseille, psychologist and supervisor in liberal. Address: AixMarseille University, LPCLS EA 3278, 13621, Aix-en-Provence, France. Email: guygimenez@me.com

Christian Bonnet, Assistant professor at the University Aix-Marseille and psychologist and supervisor in liberal. 